Provided for non-commercial research and education use. Not for reproduction, distribution or commercial use.

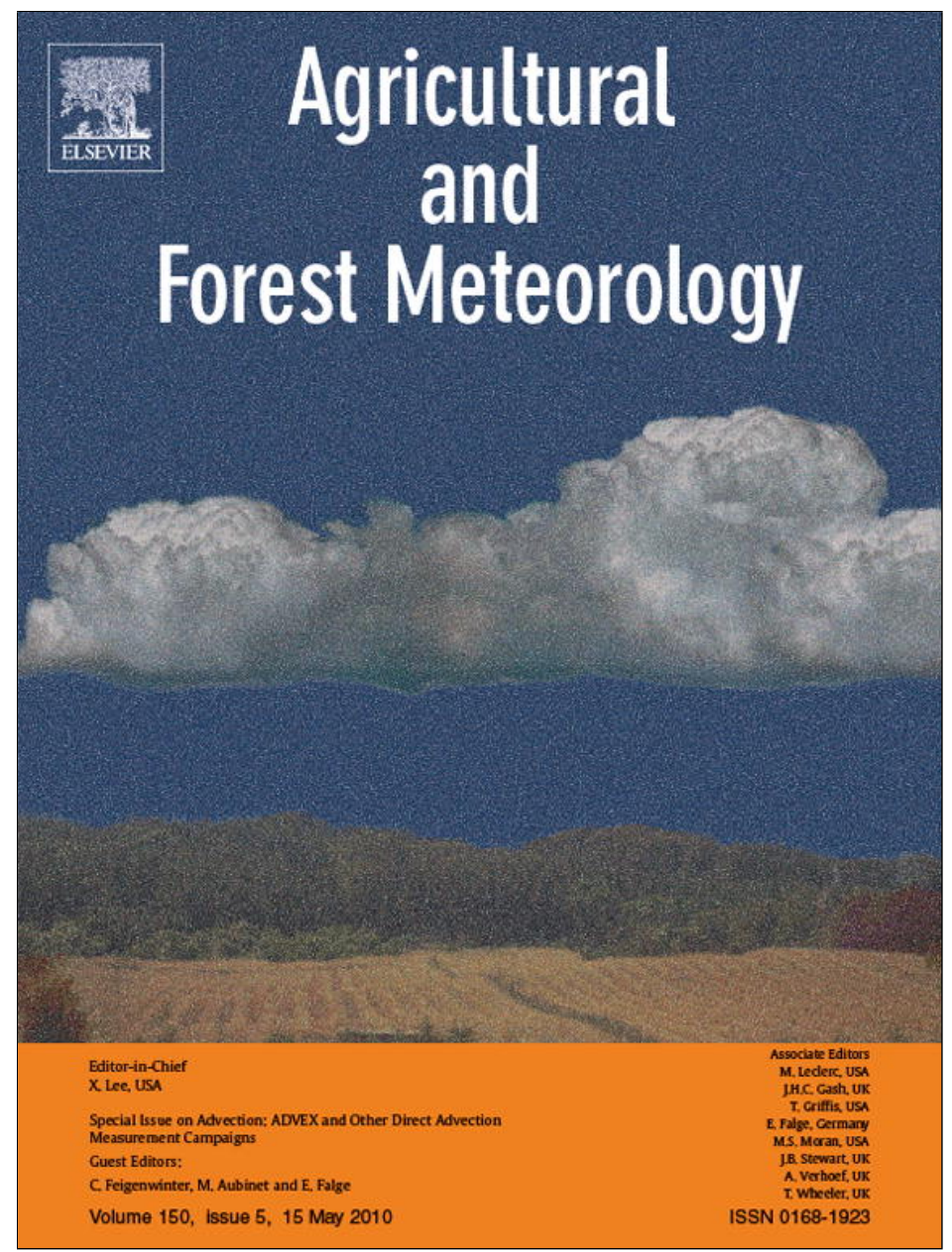

This article appeared in a journal published by Elsevier. The attached copy is furnished to the author for internal non-commercial research and education use, including for instruction at the authors institution and sharing with colleagues.

Other uses, including reproduction and distribution, or selling or licensing copies, or posting to personal, institutional or third party websites are prohibited.

In most cases authors are permitted to post their version of the article (e.g. in Word or Tex form) to their personal website or institutional repository. Authors requiring further information regarding Elsevier's archiving and manuscript policies are encouraged to visit:

http://www.elsevier.com/copyright 
Editorial

\section{Direct $\mathrm{CO}_{2}$ advection measurements and the night flux problem}

\section{Introduction}

The error affecting nighttime eddy covariance (EC) measurements and derived $\mathrm{CO}_{2}$ budgets has been extensively discussed in literature since the paper of Goulden et al. (1996). This problem is usually overcome by removing data measured during periods considered as improper for eddy covariance measurements and, when necessary, replacing them by parameterisation or more sophisticated gap-filling. Generally, the criterion used for selecting the data is based on friction velocity ( $\mathrm{u}^{*}$-filtering approach, Falge et al., 2001). However, this approach has been widely criticized as it suffers from both theoretical and practical shortcomings. On the theoretical point of view, its main flaw is that it is purely empirical and does not rely on any theoretical basis, neither for the establishment of the filtering criterion nor for the replacement of removed data. There is thus no assurance that data selection really removes only improper data and all the improper data.

As an alternative the idea of measuring all components of the mass balance in a control volume, including the advective terms, soon rose in order to have a more physically based estimate of Net Ecosystem Exchange (NEE). This relies on the hypothesis that night flux error mostly results from the emergence of non-turbulent transport processes that compete with turbulent flux under low turbulence conditions. However, measurement of non-turbulent fluxes constitutes a challenge as it requires a threedimensional approach, needing thus several measurement towers, which greatly increases the complexity and the costs of the setup compared to a single tower. Such measurements could difficultly be contemplated in a long-term perspective but should be limited to campaigns.

Several campaigns aiming at directly measuring advection have been designed recently (Aubinet et al., 2003; Feigenwinter et al., 2004; Staebler and Fitzjarrald, 2004, 2005; Marcolla et al., 2005; Heinesch et al., 2007, 2008; Tóta et al., 2008; Sun et al., 2007; Leuning et al., 2008; Yi et al., 2008). However, these different experiments are difficult to compare as the results are sensible to the design of the experimental setup and the applied methodology to derive the fluxes from measurements. The ADVEX experiment tried to overcome these limitations by applying an identical experimental setup and methodology for all three measurement campaigns.

ADVEX was invoked in the frame of the CarboEurope-IP (CEIP) project whose overarching aim was "to understand and quantify the terrestrial carbon balance of Europe and the associated uncer- tainties at local, regional and continental scale". In this frame, the ADVEX group was formed with the aims:

- to apply the best experimental setup for advection experiments; - to understand the micrometeorological and biological processes that are responsible for advective $\mathrm{CO}_{2}$-fluxes (katabatic flows, low and intermittent turbulence (stable and calm nights), source strength heterogeneities, mesoscale motions, etc.);

- to apply the most suitable method to estimate the components and the total of the advective fluxes (e.g. vertical wind components, horizontal and vertical integration of $\left[\mathrm{CO}_{2}\right]$ profiles and wind profiles, uncertainty analysis, etc.);

- to provide indication on conditions under which advection occurs;

- to provide means for correcting EC fluxes for advection ( $\mathrm{u}^{*}$, stability, storage, EC flux, wind direction, topography, etc.).

Six teams from five European countries were involved in ADVEX, performing three campaigns in 2005 (Renon/Ritten, Italy) and 2006 (Wetzstein, Germany; Norunda, Sweden) with a duration of 133, 68 and 73 days, respectively (Table 1 ).

A system (Fig. 1) of four towers fully equipped with wind velocity, temperature and $\left[\mathrm{CO}_{2}\right]$ profiles and constituting thus a control volume was installed at three European forest sites already equipped with eddy covariance systems. These sites are characterised by different topographies. All campaigns were limited to two to four months. A first presentation of the setup and of the first results was given in Feigenwinter et al. (2008).

From $\mathrm{CO}_{2}$ concentrations and wind velocity components determined in the control volume, horizontal and vertical advection were calculated for the control volume.

All papers of this special issue were presented at the "ADVEX final conference and workshop on advection" that closed the ADVEX project. They all but two refer to these measurement campaigns.

The first paper of this special issue gives an evaluation of the ability of direct advection measurements to correct the night flux error was made by Aubinet et al. (2010). They considered that the independence of wind direction and friction velocity could be used as a robustness test and analysed the evolution of vertical and horizontal advection and of advection corrected fluxes in relation to these variables. The results showed that the test failed in most cases, advection corrected fluxes varying strongly with these two variables. They show in addition that advection measurements could difficultly be used to determine when conditions for obtaining reli- 
Table 1

ADVEX organisation.

\section{ADVEX coordination}

University of Liège, Gembloux Agro-Bio Tech., Physique des Biosystèmes (M. Aubinet, C. Feigenwinter)

ADVEX teams

University of Liège, Gembloux Agro-Bio Tech., Physique des Biosystèmes, Gembloux, Belgium (M. Aubinet, C. Feigenwinter, B. Heinesch, M. Yernaux)

Max Planck Institute for Biogeochemistry, Jena, Germany (M. Hertel, O. Kolle, C. Rebmann, M. Zeri, W. Ziegler)

Lund University, GeoBiosphere Science Centre, Physical Geography and Ecosystems Analysis, Lund, Sweden (A. Lindroth, M. Mölder)

Forest Services and Agency for the Environment, Autonomous Province of Bolzano, Bolzano, Italy (S. Minerbi, L. Montagnani)

Technische Universität Dresden, Institute of Hydrology and Meteorology, Department of Meteorology, Dresden, Germany (C. Bernhofer, U. Eichelmann, U. Moderow, R. Queck)

Institute of System Biology and Ecology, Academy of Sciences of the Czech

Republic, Brno, Czech Republic (M. Acosta, D. Janous, M. Pavelka) ADVEX sites/campaigns

Renon/Ritten Italian Alps, Italy 2005 DOY 125-258

Wetzstein Thuringia, Germany 2006 DOY 102-170

Norunda Uppland, Sweden 2006 DOY 188-261

able eddy flux measurements were met. Indeed, larger advection was sometimes observed under strong winds and in flat topography, i.e. in conditions where eddy flux should supposedly give reliable estimates of the biotic flux. They concluded that a night flux correction based on direct advection measurements was hardly practicable.

However, if the results of this first paper mainly indicate the inability of direct advection measurements to correct the night flux error, the following four papers, by concentrating on site specific problems, stressed interesting mechanisms at work in the canopy and sub-canopy spaces in stable conditions.

Feigenwinter et al.(2010a) showed that advection patterns were closely linked to the local slope wind system at the alpine site Renon/Ritten. The persistent slope wind system was occasionally modified by two regio-typical synoptic weather situations: "Tramontana", a cold strong wind from the North (downslope), and "Southerlies", a moderate warm wind from the South (upslope), resulting in a substantial amplification and/or attenuation of the local slope wind system and thus the advection patterns. Despite the complex topography and heterogeneity of the vegetation, a robust diurnal course of advection developed during "normal" conditions with downslope winds and high positive advection at night and upslope winds and weak negative advection during the day. Nighttime horizontal advection was increased during "Tra-

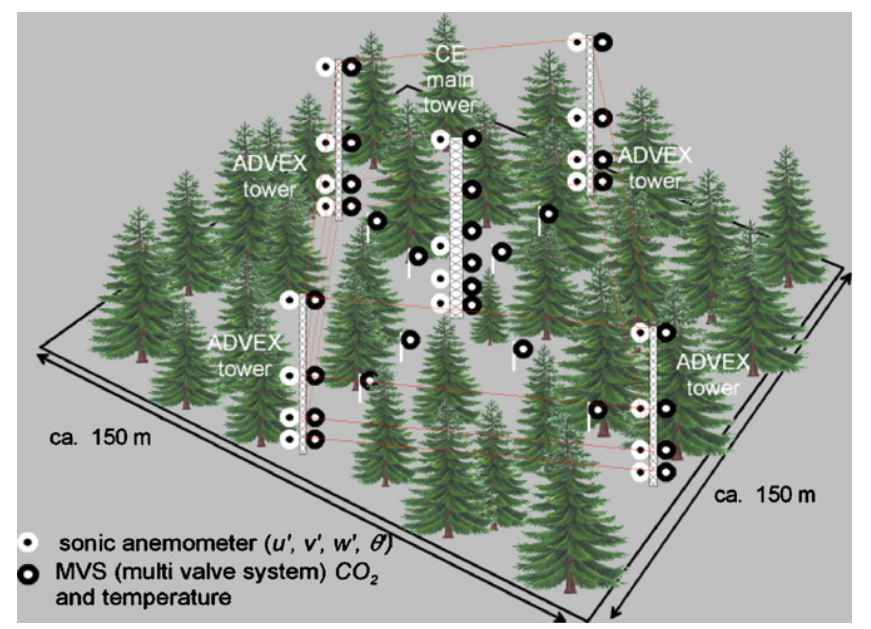

Fig. 1. General ADVEX experimental setup (adapted from Feigenwinter et al., 2008). montana" by the strong winds blowing parallel along the $\mathrm{CO}_{2}$ concentration gradient and decreased during Southerlies because of the synoptically blocked downslope flow. Including the advective fluxes into the carbon balance would significantly reduce the reported sink of this forest. However, as for all advection studies, the magnitude of this reduction was affected by considerable uncertainty.

Zeri et al. (2010) analysed advection patterns associated with cross-ridge flows at the Wetzstein site. Although advection fluxes were generally small at this site, the patterns for both directions of cross-ridge flows could be clearly related to properties of flows over vegetated hills, namely reverse flow and $\mathrm{CO}_{2}$ accumulation at the slope of the downwind side, leading to positive advection during nighttime. Though advection was gladly classified to be "site specific", it is likely that similar site topography will lead to similar qualitative advection regimes as described in these two papers.

Rebmann et al. (2010) also focused on the Wetzstein site although their results are based on a larger database, encompassing six years of measurements. They point up specific periods during which above average turbulent $\mathrm{CO}_{2}$-fluxes were detected in night conditions. They showed that these fluxes were observed under specific weather conditions and could result from advection of $\mathrm{CO}_{2}$ enriched air from some pools situated outside of the control volume. Concentrating on the site carbon balance, they showed that more realistic yearly NEE, GPP and TER sums were obtained when discarding these data from the data set. This study is one of the very rare studies to report night flux eddy covariance measurements that overestimate the biotic fluxes. Unfortunately, occurrence of such periods was seldom so that they were not observed during the ADVEX campaign at this site.

In the run-up to the ADVEX campaigns, the Norunda site was actually foreseen as the "reference site" where no advection occurs due to the nearly ideal conditions for EC-measurements. Surprise was big when realizing already after a few days of measurements, that nights with extremely large horizontal $\mathrm{CO}_{2}$ concentration gradients (and coinciding horizontal advection) frequently occurred. Feigenwinter et al. (2010b) analysed a series of such nights with large intermittent horizontal advection fluxes in the range of $50 \mu \mathrm{mol} \mathrm{m}^{-2} \mathrm{~s}^{-1}$. Since measurement errors were at least one order of magnitude smaller than these fluxes, advection was consistently negative at Norunda during the whole campaign. Applying the advection correction led to biologically unrealistic carbon budgets, the authors concluded that the ADVEX setup did obviously miss some features of advection related to both, larger (meso) and smaller (turbulence), scales.

The following four papers investigated specific properties of the wind field in forests.

One important issue is the correction of the measured wind field according to the law of mass conservation, a topic which was brought up by Vickers and Mahrt (2006), Heinesch et al. (2007) and by Leuning et al. (2008), for the computation of the vertical wind velocity, and later extended to the three dimensions by Montagnani et al. (2009).

Montagnani et al. (2010) used a correction factor $c f$ to account for mass conservation of the wind field within the external surfaces of the control volume and compare their advection computations with the results of Feigenwinter et al. (2008) for all three ADVEX sites. They conclude that the two different methods are coherent in the indication of sign (positive for Renon/Ritten and Wetzstein, negative for Norunda) and the average patterns of the mean diurnal courses, however differences were observed in the magnitude of the advective fluxes and, in particular, for some site specific wind conditions.

Canepa et al. (2010) proposed an alternative approach to compute advection by reconstructing the wind field with a mass 
conservation approach. They calculate half hourly advection at the Renon site with a "mass consistent flow model" (WINDS), which takes into account measured wind data and simulates the 3D flow field while imposing air mass conservation in the control volume. They discuss the effect of the wind field reconstruction method on the estimation of the advective fluxes and investigated the possibility of using reduced input wind data. They conclude that the representativeness of wind tower measurements is of primary importance for estimating $\mathrm{CO}_{2}$ advection terms and their uncertainty in complex terrain.

Queck and Bernhofer (2010) present a parameterisation scheme for the wind profile in and above tall vegetation canopies that accounts for the influence of the canopy architecture on the in-canopy flow under changing meteorological conditions. Furthermore, they showed that it is possible to obtain appropriate wind field information for a control volume from above-canopy wind measurements and profiles of plant area density. The application of this approach to horizontal advection calculation led to results that diverge from those of Feigenwinter et al. by $10-35 \%$

Finally, Sedlàk et al. (2010) refer to a measurement campaign that was held, preliminary to the ADVEX campaigns, in 2004 at Bily Kriz, Czech Republic. They studied nighttime airflow within a deep and dense canopy on a $13^{\circ}$ slope, near the top of a mountain ridge. A decoupled two-layer canopy flow structure was found to develop at night, above-canopy flow being upslope and lower-canopy flow mostly downslope. They develop a simplified model that gives realistic values of the major driving terms for Bily Kriz.

Many issues related to advection turned out to be extremely complex. The present special issue allows to the conclusion in Feigenwinter et al. (2008) that "some topics may be investigated in a more general way using data from all the three sites, while some characteristics of advection are highly site specific." The articles address a broad range of scientific questions to improve understanding the biomicrometeorological mechanisms of advective processes in forests.

Though there are some promising results about considering measured advective fluxes for the total ecosystem $\mathrm{CO}_{2}$ budget (e.g. Yi et al., 2008), we have to conclude that direct measurements of the advective fluxes do not fulfil the expectation for a general solution of the nighttime flux problem, as stated in the first article of Aubinet et al. (2010). As a main reason, we exhibit the incoherency of the advective fluxes, and of $F_{H A}$ in particular, with the biotic fluxes. It remains to be clarified what the measured fluxes are representative for. Nevertheless, ADVEX revealed many new insights into transport mechanisms of $\mathrm{CO}_{2}$ inside forest canopies. The results finally confirm that advection is a scale overlapping process and not restricted to calm and stable nights. Another surprising result was that even sites featuring nearly ideal conditions for the application of the EC technique were affected by advection, as shown by Feigenwinter et al. (2008, 2010b) for the Norunda site. It even seems that advection reveals more consistent patterns in so-called complex terrain where the prevailing flow regimes are influenced to an important part by the local topography. At last the question about the sense and a possible design of new advection field experiments arises. Considering the big effort in infrastructure, manpower and time consumption, a cost-benefit analysis would probably do poorly. A new experiment should cover a better resolution in the small scale in the control volume between towers as well as in the mesoscale outside the control volume, which would imply the inclusion of ground based and/or airborne remote sensing techniques like SODAR, RASS, LIDAR and other sensors. If the mass conservation approach will be applied, additional measurements should be concentrated on the control volume external surfaces. Whoever dares to invoke such a mega-experiment should always be aware that an increasing measurement resolution does not guarantee new findings by default in terms of the nighttime flux problem.

\section{References}

Aubinet, M., Heinesch, B., Yernaux, M., 2003. Horizontal and vertical $\mathrm{CO}_{2}$ advection in a sloping forest. Bound.-Lay. Meteorol. 108, 397-417.

Aubinet, M., Feigenwinter, C., Heinesch, B., Bernhofer, C., Canepa, E., Lindroth, A., Montagnani, L., Rebmann, C., Sedlak, P., Van Gorsel, E., 2010. Direct advection measurements do not help to solve the nighttime $\mathrm{CO}_{2}$ closure problem-evidence from three inherently different forests. Agric. Forest Meteorol. 150, 655-664.

Canepa, E., Georgieva, E., Manca, G., Feigenwinter, C., 2010. Application of a mass consistent flow model to study the $\mathrm{CO}_{2}$ mass balance of forests. Agric. Forest Meteorol. 150, 712-723.

Falge, E., Baldocchi, D., Olson, R., Anthoni, P., Aubinet, M., Bernhofer, C., Burba, G., Ceulemans, R., Clement, R., Dolman, H., Granier, A., Gross, P., Grünwald, T. Hollinger, D., Jensen, N.O., Katul, G., Keronen, P., Kowalski, A., Ta Lai, C., Law, B., Meyers, T., Moncrieff, J., Moors, E.J., Munger, J.W., Pilegaard, K., Rannik, U., Rebmann, C., Suyker, A., Tenhunen, J., Tu, K., Verma, S., Vesala, T., Wilson, K., Wofsy, S., 2001. Gap filling strategies for defensible annual sums of net ecosystem exchange. Agric. Forest Meteorol. 107, 43-69.

Feigenwinter, C., Bernhofer, C., Eichelmann, U., Heinesch, B., Hertel, M., Janous, D., Kolle, O., Lagergren, F., Lindroth, A., Minerbi, S., Moderow, U., Mölder, M., Montagnani, L., Queck, R., Rebmann, C., Vestin, P., Yernaux, M., Zeri, M., Ziegler, W., Aubinet, M., 2008. Comparison of horizontal and vertical advective $\mathrm{CO}_{2}$ fluxes at three forest sites. Agric. Forest Meteorol. 148, 12-24.

Feigenwinter, C., Bernhofer, C., Vogt, R., 2004. The influence of advection on short term $\mathrm{CO}_{2}$ budget in and above a forest. Boundary-layer Meteorol. 113, 201-224.

Feigenwinter, C., Montagnani, L., Aubinet, M., 2010a. Plot-scale vertical and horizontal transport of $\mathrm{CO}_{2}$ modified by a persistent slope wind system in and above an alpine forest. Agric. Forest Meteorol. 150, 665-673.

Feigenwinter, C., Mölder, M., Lindroth, A., Aubinet, M., 2010b. Spatiotemporal evolution of $\mathrm{CO}_{2}$ concentration, temperature, and wind field during stable nights at the Norunda forest site. Agric. Forest Meteorol. 150, 692-701.

Goulden, M.L., Munger, J.W., Fan, S.M., Daube, B.C., Wofsy, S.C., 1996. Measurements of carbon sequestration by long-term eddy covariance: methods and a critical evaluation of accuracy. Global Change Biol. 2, 169-182.

Heinesch, B., Yernaux, M., Aubinet, M., 2008. Dependence of $\mathrm{CO}_{2}$ advection patterns on wind direction on a gentle forested slope. Biogeosciences 5, 657-668.

Heinesch, B., Yernaux, M., Aubinet, M., 2007. Some methodological questions concerning advection measurements: a case study. Bound.-Lay. Meteorol. 122, 457-478.

Leuning, R., Zegelin, S.J., Jones, K., Keith, H., Hughes, D., 2008. Measurement of horizontal and vertical advection of $\mathrm{CO}_{2}$ within a forest canopy. Agric. Forest Meteorol. 148, 1777-1779, doi:10.1016/j.agrformet.2008.06.006.

Marcolla, B., Cescatti, A., Montagnani, L., Manca, G., Kerschbaumer, G., Minerbi, S., 2005. Importance of advection in the atmospheric $\mathrm{CO}_{2}$ exchanges of an alpine forest. Agric. Forest Meteorol. 130, 193-206.

Montagnani, L., Manca, G., Canepa, E., Georgieva, E., Acosta, M., Feigenwinter, C., Janous, D., Kerschbaumer, G., Lindroth, A., Minach, L., Minerbi, S., Mölder, M., Pavelka, M., Seufert, G., Zeri, M., Ziegler, W., 2009. A new mass conservation approach to the study of $\mathrm{CO}_{2}$ advection in an alpine forest. J. Geophys. Res.Atmos. 114, D07306, doi:10.1029/2008JD010650.

Montagnani, L., Manca, G., Canepa, E., Georgieva, E., 2010. Assessing the methodspecific differences in quantification of $\mathrm{CO}_{2}$ advection at three forest sites during the ADVEX campaign. Agric. Forest Meteorol. 150, 702-711.

Queck, R., Bernhofer, C., 2010. Constructing wind profiles in forests from limited measurements of wind and vegetation structure. Agric. Forest Meteorol. 150, 724-735.

Rebmann, C., Zeri, M., Lasslop, G., Mund, M., Kolle, O., Schulze, E.D., Feigenwinter, C., 2010. Influence of meso-scale transport processes on $\mathrm{CO}_{2}$-exchange at a complex forest site in Thuringia - Germany. Agric. Forest Meteorol. 150, 684-691.

Sedlàk, P., Aubinet, M., Heinesch, B., Janouš, D., Pavelka, M., Potužníková, K., Yernaux, M., 2010. Night-time airflow in a forest canopy near a mountain crest. Agric. Forest Meteorol. 150, 736-744.

Staebler, R.M., Fitzjarrald, D.R., 2004. Observing subcanopy $\mathrm{CO}_{2}$ advection. Agric. Forest Meteorol. 122, 139-156.

Staebler, R.M., Fitzjarrald, D.R., 2005. Measuring canopy structure and the kinematics of subcanopy flows in two forests. J. Appl. Meteorol. 44, 1161-1179.

Sun, J., Burns, S.P., Delany, A.C., Oncley, S.P., Turnipseed, A.A., Stephens, B.B., Lenschow, D.H., LeMone, M.A., Monson, R.K., Anderson, D.E., 2007. $\mathrm{CO}_{2}$ transport over complex terrain. Agric. Forest Meteorol. 145, 1-21.

Tóta, J., Fitzjarrald, D.R., Staebler, R.M., Sakai, R.K., Moraes, O.M.M., Acevedo, O.C., Wofsy, S.C., Manzi, A.O., 2008. Amazon rain forest subcanopy flow and the carbon budget: Santareǐm LBA-ECO site. J. Geophys. Res. 113, doi:10.1029/2007JG00597 G00B02.

Vickers, D., Mahrt, L., 2006. Contrasting mean vertical motion from tilt correction methods and mass continuity. Agric. Forest Meteorol. 138, 93-103. 
Yi, C., Anderson, D., Turnipseed, A Burns, S., Sparks, J., Stannard, D., Monson, R. 2008. The contribution of advective fluxes to net ecosystem exchange in a highelevation, subalpine forest. Ecol. Appl. 18 (6), 1379-1390.

Zeri, M., Rebmann, C., Feigenwinter, C., Sedlak, P., 2010. Analysis of periods with strong and coherent $\mathrm{CO}_{2}$ advection over a forested hill. Agric. Forest Meteorol. $150,674-683$.
* Corresponding author at: University of Liège, Gembloux Agro-Bio Tech., Physique des

Biosystèmes, Gembloux, Belgium.

E-mail address:Marc.Aubinet@ulg.ac.be

(M. Aubinet)

Marc Aubinet*

Christian Feigenwinter

University of Liège, Gembloux Agro-Bio Tech,

Physique des Biosystèmes, Gembloux, Belgium 